\title{
Successful Induction of Pluripotent Stem Cells From a Fabry Disease Mouse Model: Toward the Development of Safe Lentiviral Gene Therapy
}

\section{Makoto Yoshimitsu ${ }^{1,2 *}$, Koji Higuchi ${ }^{2}$, Naomichi Arima ${ }^{1}$, Jeffrey A Medin ${ }^{3}$ and Toshihiro Takenaka ${ }^{2}$}

${ }^{1}$ Division of Hematology and Immunology, Center for Chronic Viral Diseases, Graduate School of Medical and Dental Sciences, Kagoshima University, Japan ${ }^{2}$ Division of Cardiac Repair and Regeneration, Graduate School of Medical and Dental Sciences, Kagoshima University, Japan.

${ }^{3}$ Institute of Medical Science, University of Toronto, Toronto, Ontario, Canada

\begin{abstract}
Induced pluripotent stem (iPS) cells are now recognized as a valuable tool for cell repair through autologous transplantation. These cells are obtainable from somatic cells through the induction of the transcriptional factors Oct$3 / 4$, KIf4, and Sox2. In this study, we successfully established iPS cells from the tail-tip fibroblasts of a $\alpha$-galactosidase A-knockout mouse, a well-known Fabry disease mouse model. These Fabry-iPS cells exhibited an embryonic stem (ES) cell phenotype, characterized by the expression of SSEA-1, increased alkaline phosphatase activity, silencing of the retroviral-transgene, and embryoid body (EB) formation. Subcutaneous inoculation of Fabry-iPS cells into nude mice resulted in teratoma formation. At day 6 , EBs in differentiation media showed hematopoietic lineage-specific gene expression. In addition, we observed spontaneous contraction of EBs cultured on OP9 stroma cells for 5-7 days. RT-PCR demonstrated that various cardiac marker genes, such as Nkx2.5, Gata4, Tnnt2 (cardiac troponin T), and MIc2a were more highly expressed in differentiation cultures of Fabry iPS cells than of control feeder cells. To assess their potential use for gene therapy, lentiviral transduction of Fabry-iPS cells with a-galactosidase-A cDNA, the therapeutic gene for Fabry disease, was performed. This transduction resulted in elevated intracellular and secreted a-galactosidase A activity. The ES cell-specific gene expression profile remained unaltered by lentiviral therapeutic gene transfer for more than 30 days post-transduction. These findings demonstrate that Fabry-iPS cells are readily obtainable and amenable for use in gene therapy.
\end{abstract}

Keywords: a-galactosidase A; Cardiac marker genes; Embryonic stem cell; Fabry disease; Gene expression profile; Induced pluripotent stem cell; Mouse model

\section{Introduction}

Fabry disease is a lysosomal storage disorder resulting from a deficiency in $\alpha$-galactosidase A ( $\alpha$-gal A; EC 3.2.1.22) [1] and is characterized by the systemic accumulation of sphingolipids [2]. Enzyme replacement therapy is currently available for Fabry disease, and improvement in some clinical and pathological manifestations has been reported [3,4]; however, frequent infusions are required and the long-term outcome in terms of vital organ function remains unclear. Treatment of storage disorders using allogeneic cell sources has been reported [5-7]. Although overall outcomes have improved, the risks of treatment-related mortality due to engraftment failure or severe graft-versus-host disease (GvHD) continue to be the major limitations of this approach. In addition, unmodified hematopoietic stem cells (HSCs) and their progenies fail to secrete therapeutic levels of enzyme, which can also be taken up by uncorrected yet affected organs. Cells derived from autologous sources circumvent the risk of GvHD. Additionally, the transplantation of target cells that have been genetically modified to over-express and secrete the corrective enzyme promises to be more effective in maintaining therapeutic levels. We have previously shown efficient therapeutic outcomes in Fabry disease model mice after transplantation of syngeneic HSCs that had been transduced with retroviral vectors carrying a gene encoding the human $\alpha$-gal A [8-10]. However, the increased incidence of leukemias occurring in retroviral gene therapy clinical trials for X-SCID patients, due to the random integration of vectors near oncogenes, remains a major hurdle to the clinical application of this approach $[11,12]$.

Because HSCs are less capable of maintaining their stem cell phenotype during ex vivo gene-manipulation, selecting clones with safer vector-integration sites is an arduous task. In contrast, embryonic stem
(ES) cells maintain pluripotency during gene manipulation, retaining the capacity to differentiate into any cell type in vitro [13]. ES cell-based therapy, however, is complicated by immune rejection. In several recent studies, somatic cells were reprogrammed into pluripotent stem cells (termed "induced pluripotent stem cells" or iPS cells) by transduction of various transcription factors $[14,15]$. iPS cells are highly similar to ES cells in terms of their genetics, epigenetics, differentiation profiles, and ability to maintain pluripotency during genetic manipulation. Meng et al. has reported generation of iPS cells from a mouse model of Fabry disease [16]. They successfully demonstrated in vitro cardiac differentiation and in vivo multiple lineage differentiation of Fabry-iPS cells; however, in vitro hematopoietic differentiation or gene correction of iPS cells for production of the therapeutic enzyme a-gal A has not been demonstrated.

In the present study, we established Fabry mouse model-derived iPS cells, differentiated these cells in vitro into cells of a hematopoietic lineage, as well as in vivo, and transduced the cells with therapeutic lentiviral vectors to gain insights into their therapeutic potential.

*Corresponding author: Makoto Yoshimitsu, Division of Hematology and Immunology, Center for Chronic Viral Diseases, Graduate School of Medical and Dental Sciences, Kagoshima University, 8-35-1 Sakuragaoka, Kagoshima 890-8544, Japan, Tel: +81-099-275-5934; Fax: +81-99-275-5947; E-mail: myoshimi@m.kufm.kagoshima-u.ac.jp

Received December 11, 2014; Accepted January 07, 2015; Published January 09, 2015

Citation: Yoshimitsu M, Higuchi K, Arima N, Medin JA, Takenaka T (2015) Successful Induction of Pluripotent Stem Cells From a Fabry Disease Mouse Model: Toward the Development of Safe Lentiviral Gene Therapy. J Stem Cell Res Ther 5: 259. doi:10.4172/2157-7633.1000259

Copyright: (c) 2015 Yoshimitsu M, et al. This is an open-access article distributed under the terms of the Creative Commons Attribution License, which permits unrestricted use, distribution, and reproduction in any medium, provided the original author and source are credited. 


\section{Materials and Methods}

\section{a-Gal A-knockout mouse (Fabry mouse)}

a-Gal A-deficient Fabry disease model mice [17] were bred at the Kagoshima University, Kagoshima, Japan. Animal experimentation followed protocols approved by the Kagoshima University Animal Care Committee.

\section{Cell culture and establishment of Fabry mouse-derived tail- tip fibroblasts}

RF8 ES cells (kindly provided by Dr. Robert Farese of the Gladstone Institutes, San Francisco, CA) and Fabry-iPS cells were maintained on feeder layers of mitomycin C-treated mouse embryonic fibroblasts (ReproCELL, Tokyo, Japan) or mitomycin C-treated SNL 76/7 cells (European Collection of Cell Culture, Salisbury, UK) [18] in ES medium (DMEM [Invitrogen, Carlsbad, CA], containing 15\% fetal bovine serum [FBS, Invitrogen], $2 \mathrm{mM}$ L-glutamine [Invitrogen], 0.1 $\mu \mathrm{M}$ nonessential amino acids [Invitrogen], $0.1 \mu \mathrm{M}$ 2-mercaptoethanol [Invitrogen], and 50 units/ml each of penicillin and streptomycin [Invitrogen]). As a source of leukemia inhibitory factor (LIF), we used human recombinant LIF (1:1000 dilution, Wako, Tokyo, Japan) or SNL feeder cells that had been clonally derived from the STO cell line transduced with LIF cDNA [18].

Plat-E packaging cells (kindly provided by Dr. Toshio Kitamura, University of Tokyo, Tokyo, Japan) [19], which were used to produce retroviruses, were maintained in DMEM containing 10\% FBS, 50 units/ $\mathrm{ml}$ each of penicillin and streptomycin, $1 \mu \mathrm{g} / \mathrm{ml}$ puromycin (SigmaAldrich, St Louis, MO), and $100 \mu \mathrm{g} / \mathrm{ml}$ blasticidin S (Funakoshi, Tokyo, Japan). OP9 cells (RIKEN BRC Cell Bank, Ibaraki, Japan) were maintained in alpha-MEM (Invitrogen) containing 20\% FBS, 100 units/ $\mathrm{ml}$ each of penicillin and streptomycin. Tail-tip fibroblasts (TTFs) were established from Fabry mice as previously described [20].

\section{Retroviral vector production and infection}

One day prior to transduction, Plat-E cells [19] were seeded at 3.5 $\times 10^{6}$ cells per $100-\mathrm{mm}$ tissue culture dish. On the next day, pMXsbased retroviral vectors (pMXs-Oct3/4, pMXs-Klf4, and pMXs-Sox2, obtained from Addgene, Cambridge, MA) [14] were introduced into these cells using Fugene 6 transfection reagent (Roche, Mannheim, Germany) as per the manufacturer's instructions. Twenty-seven microliters of Fugene 6 was diluted in $300 \mu$ lof Opti-MEM (Invitrogen) and incubated for $5 \mathrm{~min}$ at room temperature. Nine micrograms of each plasmid was added to the mixture, which was incubated for another $15 \mathrm{~min}$ at room temperature. Thereafter, the respective DNA/Fugene 6 mixtures were added dropwise to the Plat-E cells. Cells were then incubated overnight at $37^{\circ} \mathrm{C}$ under $5 \% \mathrm{CO}_{2}$. Twenty-four hours after transfection, the medium was replaced.

Fabry-TTFs were seeded at $4 \times 10^{5}$ cells per 100 -mm dish on the day before transduction. Forty-eight hours after transfection, viral vector-containing supernatants from transfected Plat-E cells were collected and filtered through $0.45 \mu \mathrm{m}$ filters (Millipore, Billerica, MA) and supplemented with $4 \mu \mathrm{g} / \mathrm{ml}$ polybrene (Nacalai Tesque, Tokyo, Japan). Target cells were incubated in the virus/polybrene-containing supernatants overnight. Three days after infection, $4 \times 10^{4}$ to $4 \times 10^{5}$ transduced cells were plated onto mitomycin C-treated SNL feeder cells in ES medium. Clones with ES cell-like morphology were selected after 2-3 weeks.

\section{Flow cytometric analysis and alkaline phosphatase staining}

Fabry-iPS cells were stained using phycoerythrin (PE)-conjugated anti-mouse SSEA-1 antibody (clone MC-480, BioLegend, San Diego, CA) or PE-conjugated mouse IgM isotype control (clone MM-30, BioLegend). Cells were then analyzed by flow cytometry using a FACScan (BD Biosciences, San Jose, CA) and data were analyzed using FlowJo (Tree Star Inc., Ashland, OR). Alkaline phosphatase staining was performed using the Alkaline Phosphatase Detection Kit (Millipore) as per the manufacturer's instructions.

\section{Reverse transcriptional PCR and Real time PCR for marker genes}

Total RNA was extracted using RNAqueous (Applied Biosystems, Foster City, CA). We performed reverse transcription using a High Capacity cDNA Reverse Transcription Kit (Applied Biosystems). PCR was done with KOD-plus (TOYOBO, Osaka, Japan). Primer sequences and PCR conditions were as previously described $[21,22]$.

Real-time PCR was performed with Taqman Universal PCR Master Mix (Applied Biosystems) and Taqman Gene Expression Assays (Applied Biosystems). The Taqman Gene Expression Assays used were as follows: Nanog (Assay ID: Mm02384862_g1), Zfp42 (Mm01194090_g1), Utf1 (Mm00447703_g1), Eras (Mm03053919_s1), Gata1 (Mm01352636_ m1), Gata2 (Mm00492299_g1), Runx1 (Mm01213405_m1), Scl/Tal1 (Mm01187033_m1), Sfpi1 (Mm01213405_m1), Mesp1 (Mm00801883_ g1), Brachyury (Mm01318252_m1), Gata4 (Mm00484689_m1), Tnnt2 (Mm00441922_m1), Mlc2a (Mm00440384_m1), and Gapdh (Mm99999915_g1). The PCR conditions were as follows: $50^{\circ} \mathrm{C}$ for 2 min, $95^{\circ} \mathrm{C}$ for $10 \mathrm{~min}, 40$ cycles each consisting of $95^{\circ} \mathrm{C}$ for $15 \mathrm{~s}$ and $60^{\circ} \mathrm{C}$ for $1 \mathrm{~min}$. Signals were detected with an ABI7300 Real-Time PCR System (Applied Biosystems).

\section{Teratoma formation}

Fabry-iPS cells were suspended at $5 \times 10^{7}$ cells $/ \mathrm{ml}$ in phosphatebuffered saline (PBS; Invitrogen). Nude mice were anesthetized with 100 $\mathrm{mg} / \mathrm{kg}$ bodyweight of ketamine and $10 \mathrm{mg} / \mathrm{ml}$ of xylazine. We injected $20 \mu \mathrm{l}$ of the cell suspension $\left(1 \times 10^{6}\right.$ cells $)$ subcutaneously into both inguinal regions. Five weeks after the injection, tumors were surgically dissected from the mice. Samples were fixed in PBS containing 4\% formaldehyde, and embedded in paraffin. Sections were stained with hematoxylin and eosin.

\section{In vitro differentiation of iPS cells into hematopoietic lineage cells}

For EB differentiation, cells were harvested by trypsinization and transferred to gelatin-coated dishes in ES media lacking LIF for $1 \mathrm{~h}$ to allow feeder cells to adhere. Non-adherent cells were collected, resuspended in differentiation media (IMDM [Invitrogen] containing 15\% differentiation serum [StemCell Technologies, Vancouver, Canada], $200 \mu \mathrm{g} / \mathrm{ml}$ holo-transferrin [Sigma], $4.5 \mathrm{mM}$ monothioglycerol [Sigma], $50 \mu \mathrm{g} / \mathrm{ml}$ ascorbic acid [Sigma], $2 \mathrm{mM} \mathrm{L}$-glutamine, and $50 \mathrm{U}$ and 50 $\mathrm{mg} / \mathrm{ml}$ of penicillin and streptomycin, respectively), in hanging drops at a concentration of 100 cells per $15 \mu \mathrm{l}$ drop, in an inverted petri dish. EBs were collected from the hanging drops at day 2 and transferred into $10 \mathrm{ml}$ differentiation media in slowly rotating $10-\mathrm{cm}$ petri dishes. At day 4, EBs was fed by exchanging half of the spent medium for fresh differentiation media. Cells were harvested at day 6 by collagenase treatment and the expression of hematopoietic-specific genes was then analyzed [23].

\section{In vitro differentiation of iPS cells into cardiac lineage cells}

Five days after EB differentiation in ES media lacking LIF, EBs were plated onto OP9 cells for another 5-7 days for cardiac lineage 
Citation: Yoshimitsu M, Higuchi K, Arima N, Medin JA, Takenaka T (2015) Successful Induction of Pluripotent Stem Cells From a Fabry Disease Mouse Model: Toward the Development of Safe Lentiviral Gene Therapy. J Stem Cell Res Ther 5: 259. doi:10.4172/2157-7633.1000259

Page 3 of 6

differentiation. Spontaneously contracting cells were harvested between days 10 and 12 by collagenase treatment and the expression of cardiac lineage-specific genes was then analyzed.

\section{Lentiviral vector production and transduction of Fabry-iPS cells}

The lentiviral vector plasmid, pHR'-EF1 $\alpha$-human $\alpha$-gal A-WPRESIN (LV/human a-gal A), expressing human a-gal A, was used as previously described [10]. Vesicular stomatitis virus glycoproteinpseudotyped lentiviral vectors were generated by transient transfection of 293T cells (ATCC, Manassas, VA) using the three-plasmid system (lentiviral vector plasmid constructs, the packaging plasmid pCMV $\triangle$ R8.91, and the vesicular stomatitis virus glycoprotein envelope-coding plasmid, pMD.G) [24]. Transfections were performed with FuGENE6 (Roche). Supernatants containing viral particles were collected $48 \mathrm{~h}$ later for use in transduction.

\section{a-Gal A activity assay}

Alpha-Gal A activity was measured by a fluorometric assay as previously described [25]. Samples were added to a microtiterplate reader (Twinkle LB970, Berthold Technology), and the 4-methylumbelliferone product was determined quantitatively by comparison with known standards (Sigma). Cell pellets were sonicated for $10 \mathrm{~s}$ in assay buffer $(28 \mathrm{mM}$ citric acid/44 $\mathrm{mM}$ disodium phosphate, $\mathrm{pH} 4.4$ ) with $5 \mathrm{mg} / \mathrm{ml}$ sodium taurocholate.

\section{Results}

\section{Establishment of Fabry-iPS cells}

Fabry-TTFs were transduced simultaneously with pMXs retroviral vectors encoding three transcriptional factors (mouse Oct3/4, mouse Sox2, and mouse Klf4), along with the enGFP marker gene. Transduction efficiency was determined by enGFP expression: more than $95 \%$ of Fabry-TTFs expressed the marker gene as assessed by flow cytometric analysis (Figure 1A). An ES cell-like morphology was discernible 14 days after transduction (Figure 1B). Between day 14 and day 21 after transduction, 20 colonies with ES cell-like morphology were picked for further expansion. To determine whether those cells expressed ES cell-specific markers, stage-specific embryonic antigen 1 (SSEA-1) expression was analyzed by flow cytometry. As shown in Figure 1 C, more than $90 \%$ of those cells expressed SSEA-1. In addition, enGFP expression was almost completely silenced, indicating that the retrovirally transduced cells were in an ES cell state (Figure 1C).

Alkaline phosphatase activity, another major phenotype of the ES cell state, was assessed by alkaline phosphatase staining. SSEA-1 (+)/ enGFP (-) clones stained for this enzyme (Figure 1D). Expression of
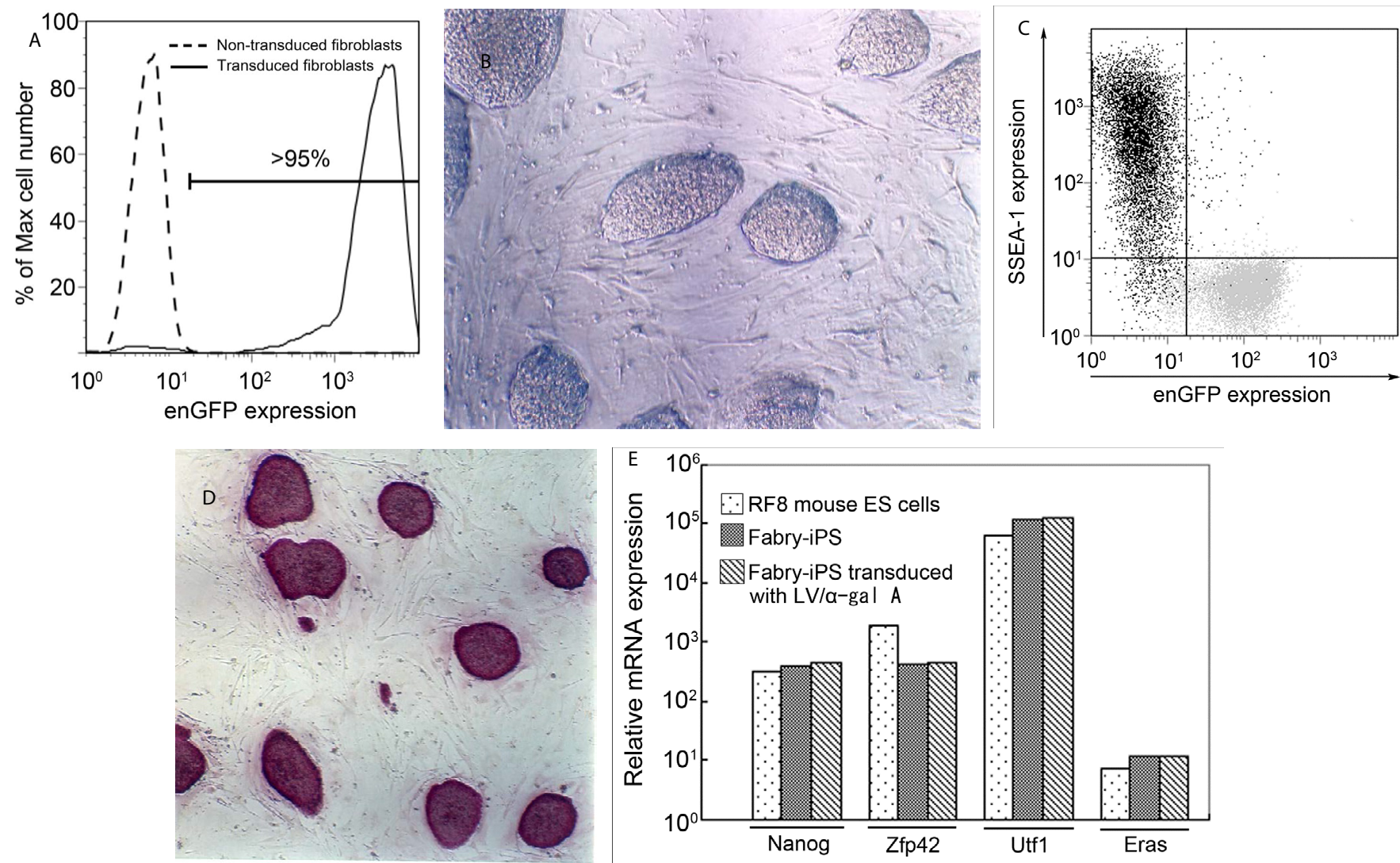

Figure 1: Embryonic stem (ES) cell-like colonies produced from Fabry mouse-derived induced pluripotent stem (iPS) cells

(A) Transduction of Fabry-TTFs with pMXs-enGFP retrovirus generated in Plat-E packaging cells.

(B) Morphology of ES cell-like colonies.

(C) SSEA-1 expression, with enGFP-silencing, in ES cell-like colonies. Mouse Oct3/4-, KIf4-, Sox2- and enGFP-transduced Fabry-TTFs were used as a control (gray dots).

(D) Alkaline phosphatase staining of ES cell-like colonies

(E) Relative ES cell-specific gene expression in Fabry-iPS cells. Real-time PCR analysis of ES cell marker genes in ES cells (RF8), Fabry-iPS cells, Fabry-TTFs, and LV/a-gal A-transduced Fabry-iPS cells. Values indicate the relative mRNA levels normalized to Fabry-TTFs. Gapdh was used as an internal control. 
Citation: Yoshimitsu M, Higuchi K, Arima N, Medin JA, Takenaka T (2015) Successful Induction of Pluripotent Stem Cells From a Fabry Disease Mouse Model: Toward the Development of Safe Lentiviral Gene Therapy. J Stem Cell Res Ther 5: 259. doi:10.4172/2157-7633.1000259

Page 4 of 6

other ES cell markers was determined by real-time PCR. As shown in Figure 1E, Nanog, Zfp 42, Utf1, and Eras mRNAs were induced in the cells to levels comparable to those in a control mouse ES cell line (RF8). Non-transduced Fabry-TTFs were used as negative controls.

\section{In vivo differentiation of Fabry-iPS cells}

Next, we examined the pluripotency of iPS cells by assessing their ability to induce teratoma formation. We observed tumors after subcutaneous inguinal injections of these cells into nude mice (Figure 2A). Histological examination revealed that the injected iPS cells differentiated into all three germ layers (Figure 2B).

\section{In vitro differentiation of Fabry-iPS cells}

The above data demonstrated that the iPS clones exhibited an ES cell phenotype. We then analyzed the in vitro differentiation capacity of Fabry-iPS cells. iPS cells formed EBs in non-coated plastic dishes (Figure 3A). Six days after inducing EB formation in differentiation cultures (EB6), Gata1, Gata2, Runx1, Scl/Tal1, and Sfpi1 mRNA expression was up-regulated when compared to the levels in FabryiPS cells, as determined by real-time PCR, while ES cell-specific genes (Nanog, Zfp 42, Utf1) were markedly down-regulated (Figure 3B). Thus, we confirmed that iPS cells were capable of differentiation into cells of a hematopoietic lineage, indicating a target for a gene therapy approach in future.
For cardiac lineage differentiation of iPS cells, spontaneously contracting EBs could be induced from EBs cultured for 5-7 days on OP9 stroma cells (data not shown). Real-time PCR demonstrated that various cardiac marker genes, such as Nkx2.5, Gata4, Tnnt2, and Mlc2a, were highly expressed in differentiation cultures of Fabry-iPS cells as compared to control feeder cells (Figure 4A and 4B).

\section{Lentiviral transduction of Fabry-iPS cells}

Fabry-iPS cells were transduced with lentiviral vector/enGFP at a multiplicity of infection (MOI) of 84 (57.8 ng p24 antigen for 1 $\times 10^{5}$ Fabry-iPS cells), and enGFP expression was measured by flow cytometry with SSEA-1 co-staining at 4 days after transduction. As shown in Figure 4C, Fabry-iPS cells were efficiently transduced with lentiviral vector/enGFP vectors (up to 60\%) and still maintained the expression of SSEA-1.

Next, we examined therapeutic gene transfer into Fabry-iPS cells using a human $\alpha$-gal A lentiviral vector (LV/a-gal A). Fabry-iPS cells (1 $\times 10^{5}$ ) were transduced with $55.6 \mathrm{ng}$ p24 antigen of LV/a-gal A. Thirty days after transduction; intracellular $\alpha$-gal A activity was measured. a-Gal A activity was elevated in LV/a-gal A-transduced Fabry-iPS cells by more than 1.7-fold higher than that of normal RF8 ES cells (Figure 4D). In addition, $\alpha$-gal A activity in the culture media from the LV/ $\alpha$ gal A-transduced Fabry-iPS cells was assessed to measure the activity of
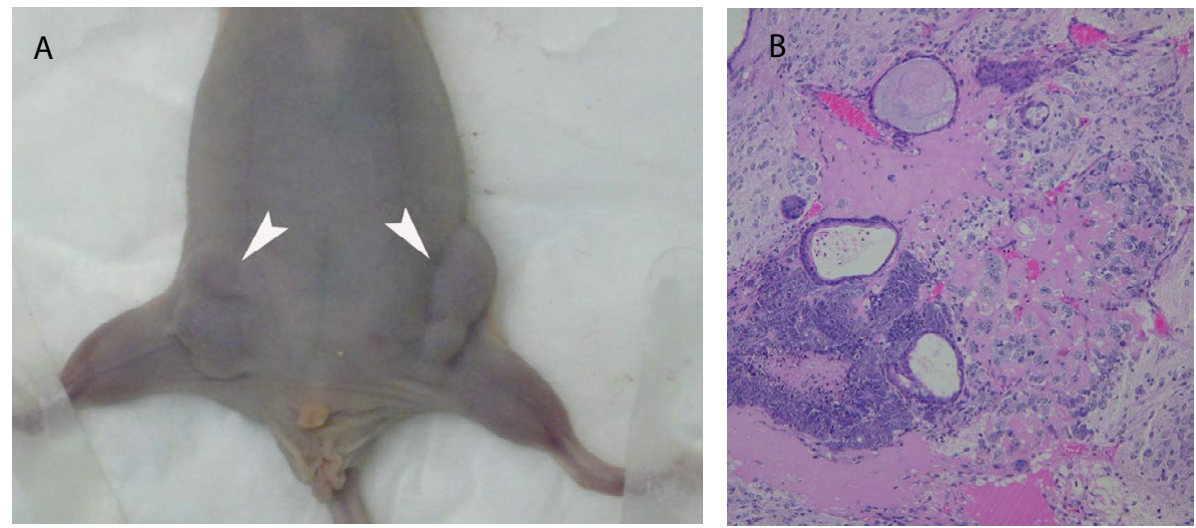

Figure 2: Teratoma formation by Fabry-iPS cells. Fabry-iPS cells were subcutaneously transplanted into nude mice. After 5 weeks, teratomas were photographed. (A) Analyzed histologically with hematoxylin.

(B) Eosin staining.
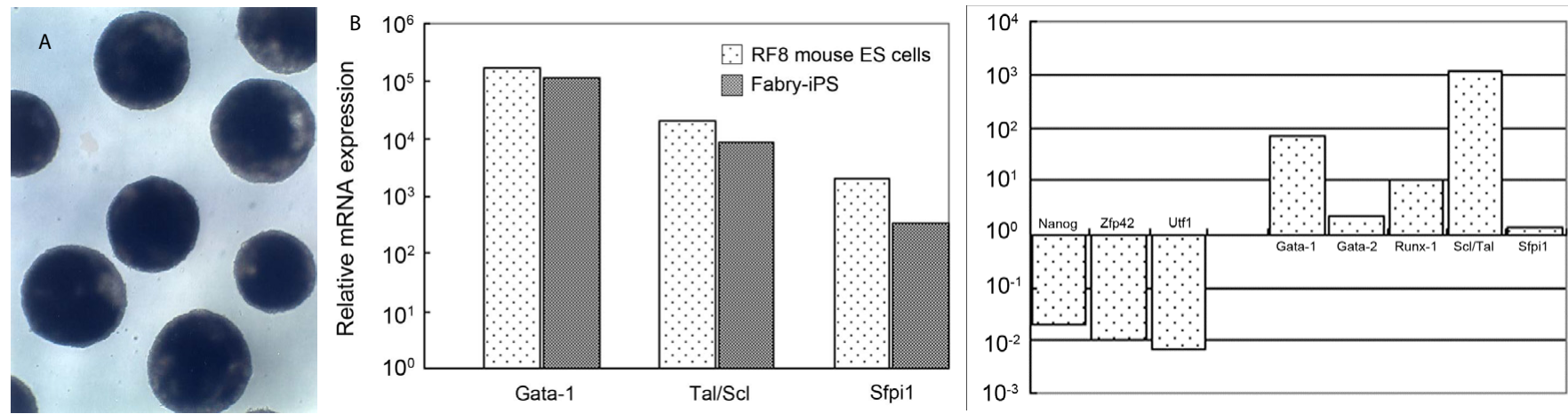

Figure 3: Differentiation of Fabry-iPS cells into cells of a hematopoietic lineage

(A) In vitro embryoid body formation. Embryoid bodies were photographed 5 days after induction

(B) In vitro differentiation of Fabry-iPS cells into cells of a hematopoietic lineage. Gene expression is shown relative to that in Fabry-iPS cells. Quantitative RT-PCR analysis of embryonic stem (ES) cell-specific and hematopoietic lineage marker genes in day 6 embryoid bodies. Gapdh was used as an internal control 

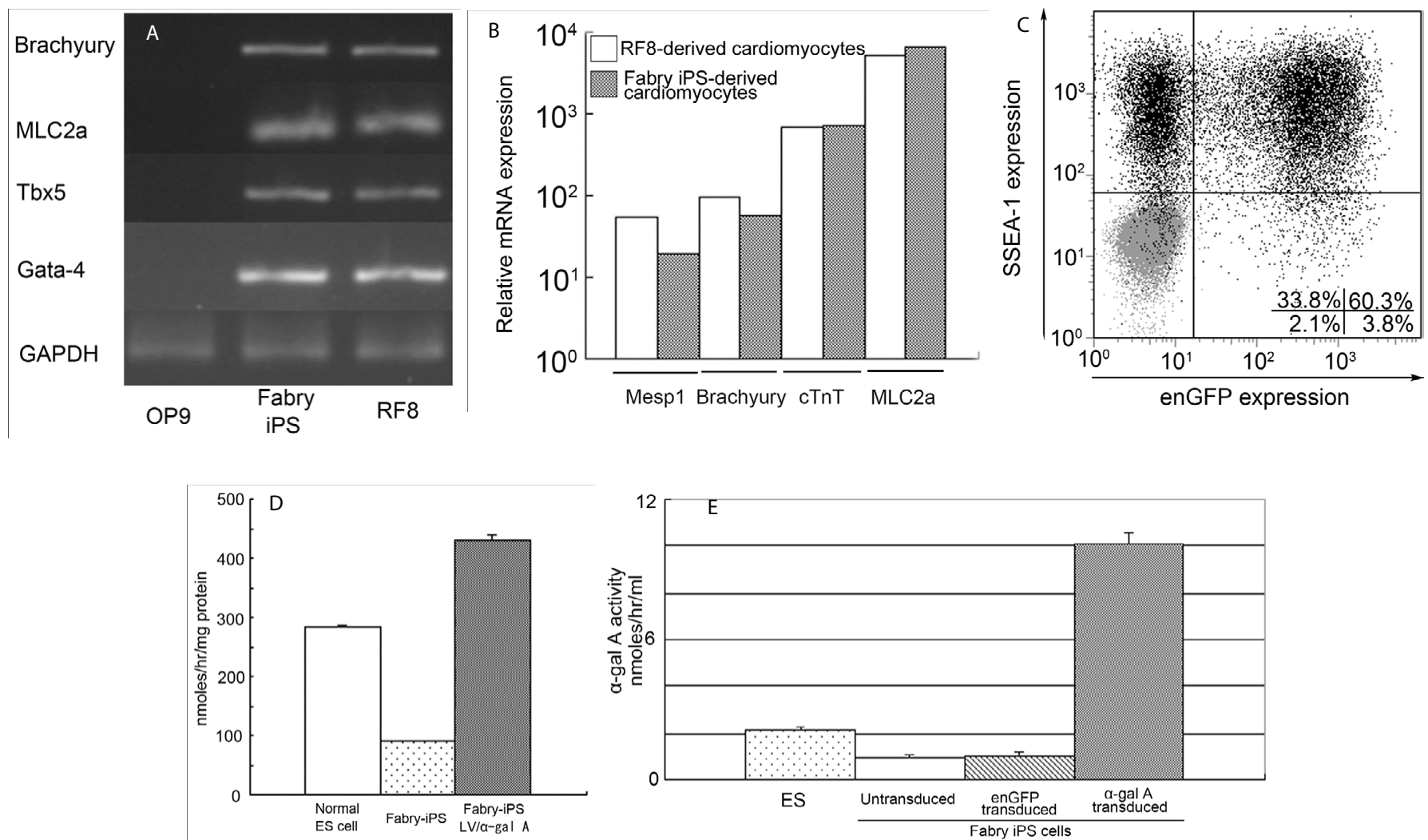

Figure 4: Differentiation of Fabry-iPS cells into cells of a cardiac lineage and transduction of Fabry-iPS cells with lentiviral vectors

(A) In vitro differentiation of Fabry-iPS cells into cardiac lineage. RT-PCR analysis of cardiac lineage-specific genes in contracting cells, OP9 stroma cells, and mouse embryonic stem cells (RF8). Gapdh was used as an internal control.

(B) In vitro differentiation of Fabry-iPS cells into cells of a cardiac lineage. Real-time PCR analysis of cardiac lineage marker genes in Fabry-iPS-derived contracting cells and mouse ES cell (RF8)-derived contracting cells. Gapdh was used as an internal control.

(C) Transduction of Fabry-iPS cells with a lentiviral vector (LV)/enGFP vector at a multiplicity of infection of 84 . Transduced Fabry-iPS cells maintained SSEA-1 expression (upper right panel).

(D) Intracellular $\alpha$-galactosidase A ( $\alpha$-gal A) activity in LV/a-gal A-transduced Fabry-iPS cells

(E) Secreted $\alpha$-gal A activity in LV/a-gal A-transduced Fabry-iPS cells.

the secreted form of $\alpha$-gal A. $\alpha$-Gal A was secreted in culture media of the transduced Fabry-iPS cells at levels 5-fold higher than those in the media from RF8 cells (Figure 4E).

\section{Discussion}

In the present study, we established Fabry mouse-derived iPS cells with the transduction of defined factors and confirmed their pluripotency in vitro and in vivo. Fabry-iPS cells were also efficiently and functionally transduced with therapeutic lentiviral vectors. Identification of the vector integration sites in transduced Fabry-iPS cells by inverse PCR is currently under investigation. One of the most important applications of disease-specific iPS cells is to create relevant in vitro disease models. In this study, Fabry-iPS cell derived cardiomyocytes were differentiated from Fabry mouse model derived cells. This in vitro model could be used to explore the pathological mechanism of cardiac Fabry disease. Kawagoe et al. recently reported generation of cells with the morphological features of iPS cells from Fabry patient-derived skin fibroblasts [26]. They also demonstrated expression of high levels of alkaline phosphatase, SSEA-4, TRA-1-60, and TRA-1-81; however, they did not demonstrate teratoma formation or differentiation of several cell type lineages. Those authors claimed that the difficulty of differentiation of these iPS cells into cardiomyocytes was due to accumulation of membranous cytoplasmic bodies in lysosomes. However, these findings need to be confirmed using other Fabry patient-derived fibroblasts, since the induction efficacy varies in fibroblasts from independent origins. In addition, further in vivo studies are warranted for investigating i) whether therapeutically corrected iPS cells, employing safer vector integration approaches, are indeed safe, ii) the development of efficient and stringent methods for differentiation of these cells into tissue stem cells, including HSCs, avoiding formation of teratomas, and iii) the long-term outcome of therapeutic intervention using therapeutically manipulated and differentiated iPS in relevant animal models.

\section{Acknowledgments}

We thank Miss Miho Hachiman and Aya Hamada for their technical assistance.

\section{References}

1. Brady RO, Gal AE, Bradley RM, Martensson E, Warshaw AL, et al. (1967) Enzymatic defect in Fabry's disease. Ceramidetrihexosidase deficiency. N Engl J Med 276: 1163-1167. [PubMed]

2. Desnick RJ, Eng CM (2001) Fabry disease. McGraw-Hill Inc, New York.

3. Eng CM, Guffon N, Wilcox WR, Germain DP, Lee P, et al. (2001) Safety and efficacy of recombinant human alpha-galactosidase A--replacement therapy in Fabry's disease. N Engl J Med 345: 9-16. [PubMed]

4. Schiffmann R, Kopp JB, Austin HA 3rd, Sabnis S, Moore DF, et al. (2001) Enzyme replacement therapy in Fabry disease: a randomized controlled trial. JAMA 285: 2743-2749. [PubMed] 
Citation: Yoshimitsu M, Higuchi K, Arima N, Medin JA, Takenaka T (2015) Successful Induction of Pluripotent Stem Cells From a Fabry Disease Mouse Model: Toward the Development of Safe Lentiviral Gene Therapy. J Stem Cell Res Ther 5: 259. doi:10.4172/2157-7633.1000259

5. Boelens JJ, Wynn RF, O'Meara A, Veys P, Bertrand Y, et al. (2007) Outcomes of hematopoietic stem cell transplantation for Hurler's syndrome in Europe: a risk factor analysis for graft failure. Bone Marrow Transplant 40: 225-233. [PubMed]

6. Staba SL, Escolar ML, Poe M, Kim Y, Martin PL, et al. (2004) Cord-blood transplants from unrelated donors in patients with Hurler's syndrome. $\mathrm{N}$ Engl $\mathrm{J}$ Med 350: 1960-1969. [PubMed]

7. Beam D, Poe MD, Provenzale JM, Szabolcs P, Martin PL, et al. (2007) Outcomes of unrelated umbilical cord blood transplantation for $X$-linked adrenoleukodystrophy. Biol Blood Marrow Transplant 13: 665-674. [PubMed]

8. Takenaka T, Murray GJ, Qin G, Quirk JM, Ohshima T, et al. (2000) Longterm enzyme correction and lipid reduction in multiple organs of primary and secondary transplanted Fabry mice receiving transduced bone marrow cells. Proc Natl Acad Sci USA 97: 7515-7520. [PubMed]

9. Qin G, Takenaka T, Telsch K, Kelley L, Howard T, et al. (2001) Preselective gene therapy for Fabry disease. Proc Natl Acad Sci USA 98: 3428-3433. [PubMed]

10. Yoshimitsu M, Higuchi K, Ramsubir S, Nonaka T, Rasaiah VI, et al. (2007) Efficient correction of Fabry mice and patient cells mediated by lentivira transduction of hematopoietic stem/progenitor cells. Gene Ther 14: 256-265. [PubMed]

11. Hacein-Bey-Abina S, Von Kalle C, Schmidt M, McCormack MP, Wulffraat N, et al. (2003) LMO2-associated clonal T cell proliferation in two patients after gene therapy for SCID-X1. Science 302: 415-419. [PubMed]

12. Hacein-Bey-Abina S, Garrigue A, Wang GP, Soulier J, Lim A, et al. (2008) Insertional oncogenesis in 4 patients after retrovirus-mediated gene therapy of SCID-X1. J Clin Invest 118: 3132-3142. [PubMed]

13. Lerou PH, Daley GQ (2005) Therapeutic potential of embryonic stem cells. Blood Rev 19: 321-331. [PubMed]

14. Takahashi K, Yamanaka S (2006) Induction of pluripotent stem cells from mouse embryonic and adult fibroblast cultures by defined factors. Cell 126 : 663-676. [PubMed]

15. Takahashi K, Tanabe K, Ohnuki M, Narita M, Ichisaka T, et al. (2007) Induction of pluripotent stem cells from adult human fibroblasts by defined factors. Cell 131: 861-872. [PubMed]
16. Meng XL, Shen JS, Kawagoe S, Ohashi T, Brady RO, et al. (2010) Induced pluripotent stem cells derived from mouse models of lysosomal storage disorders, Proc Natl Acad Sci USA 107: 7886-7891. [PubMed]

17. Ohshima T, Murray GJ, Swaim WD, Longenecker G, Quirk JM, et al. (1997) alpha-Galactosidase A deficient mice: a model of Fabry disease, Proc Nat Acad Sci USA 94: 2540-2544. [PubMed]

18. McMahon AP, Bradley A (1990) The Wnt-1 (int-1) proto-oncogene is required for development of a large region of the mouse brain. Cell 62: 1073-1085. [PubMed]

19. Morita S, Kojima T, Kitamura T (2000) Plat-E: an efficient and stable system for transient packaging of retroviruses. Gene Ther 7: 1063-1066. [PubMed]

20. Takahashi K, Okita K, Nakagawa M, Yamanaka S (2007) Induction of pluripotent stem cells from fibroblast cultures. Nat Protoc 2: 3081-3089. [PubMed]

21. Narazaki G, Uosaki H, Teranishi M, Okita K, Kim B, et al. (2008) Directed and systematic differentiation of cardiovascular cells from mouse induced pluripotent stem cells. Circulation 118: 498-506. [PubMed]

22. Mauritz C, Schwanke K, Reppel M, Neef S, Katsirntaki K, et al. (2008) Generation of functional murine cardiac myocytes from induced pluripotent stem cells. Circulation 118: 507-517. [PubMed]

23. McKinney-Freeman SL, Naveiras O, Daley GQ (2008) Isolation of hematopoietic stem cells from mouse embryonic stem cells. Curr Protoc Stem Cell Biol. [PubMed]

24. Naldini L, Blömer U, Gallay P, Ory D, Mulligan R, et al. (1996) In vivo gene delivery and stable transduction of nondividing cells by a lentiviral vector. Science 272: 263-267. [PubMed]

25. Mayes JS, Scheerer JB, Sifers RN, Donaldson ML (1981) Differential assay for lysosomal alpha-galactosidases in human tissues and its application to Fabry's disease. Clin Chim Acta 112: 247-251. [PubMed]

26. Kawagoe S, Higuchi T, Otaka M, Shimada Y, Kobayashi H, et al. (2013) Morphological features of iPS cells generated from Fabry disease skin fibroblasts using Sendai virus vector (SeVdp). Mol Genet Metab 109: 386-389. [PubMed] 